\title{
НЕЙРОПСИХОЛОГИЧЕСКИЕ ОСНОВАНИЯ НРАВСТВЕННОСТИ
}

Авдулова Т.П. (Московский педагогический государственный университет, Москва, Россия) avdulova@bk.ru

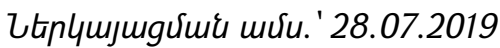

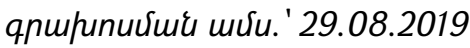

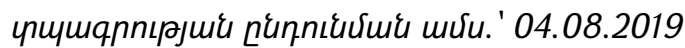

Эмпирическое исследование нейропсихологических оснований морального развития проводилось на выборке из 82 детей дошкольного возраста. Изучалась взаимосвязь между становлением моральной сферы ребенка и нейропсихологическим уровнем, обусловленным созреванием и дебютом мозговых структур. Дети с недостаточной сформированностью нейроструктур демонстрируют низкий уровень морального развития. Были выявлены следующие факторы мозговой зрелости: способность удерживать и воспроизводить программу (динамический праксис); способность оценивать и воспроизводить ритмические структуры (акустический гнозис); способность к перешифровке воспринимаемого образа (зрительно-пространственный праксис). Кроме того, обнаружены значимые различия между мальчиками и девочками по нейропсихологическим показателям и уровню следования внешним правилам, а также уровню самоконтроля. В моральном развитии значимых различий между полами выявлено не было. На поведенческом уровне низкие показатели нейропсихологической организации проявились низким уровнем произвольности в реальных ситуациях у $44 \%$ детей. Были также обнаружены двухсторонние значимые корреляционные связи между нейропсихологическим уровнем и уровнем самоконтроля. Обнаружена значимая отрицательная корреляционная связь между показателями нейропсихологического уровня и способностью к принятию социальных норм и ценностей.

Ключевые слова: моральное развитие, дошкольный возраст, нейропсихология, произвольность, гнозис, праксис.

Постановка проблемы. Созревание в старшем дошкольном возрасте ряда нейроструктур, которые в дальнейшем определяют развитие когнитивных процессов и обучаемости, хронологически и содержательно связано с формированием системы нравственных представлений и регуляторных структур, обеспечивающих реализацию детьми моральных норм и правил в поведении. Еще Ж. Пиаже строил систему морального онтогенеза с опорой на общее биологическое созревание когнитивных структур, проявляющих себя и реализующихся в социальных связях [7]. Положения Л.С. Выготского и А.Р. Лурия о системной 
динамической локализации высших психических функций, о качественных возрастных переходах и системном, интегрированном функционировании нейроструктур послужили точкой отсчета в нашем исследовании. Отметим, что прямых исследований моральной сферы дошкольников во взаимосвязи с нейропсихологическим базисом развития крайне мало и в основном они сосредоточены на показателях фризиологической зрелости. Помимо этого, детская нейропсихология преимущественно сосредоточена на дизонтогенезе и задачах абилитации, восстановления и адаптации когнитивных процессов. Тогда как модели нормативного развития для анализа и системного использования влияния нейроструктур на высшие психические процессы, в части на моральное развитие, у детей фактически не реализовывались [3].

Еще одним принципиальным моментом исследований данного типа являются трудности переноса данных, полученных в нейропсихологии на поведенческие модели. Типичным примером теоретических объяснительных пустот, возникающих между знаниями разного рода, являются исследования зеркальных нейронов как основы развития эмпатии [6]. С одной стороны многие эмоциональные процессы объясняются функцией зеркальных нейронов, а в раннем онтогенезе предпосылками возникновения эмпатии становятся процессы эмоционального заражения. Однако напрямую связать интенсивность функционирования зеркальных нейронов со сложным механизмом эмпатии не удалось. Требуются промежуточные объяснительные модели.

Вместе с тем, уже к концу младшего школьного возраста мы можем уверенно говорить не только о формировании когнитивного стиля, но и морального стиля восприятия, обработки и интерпретации информации в моральной сфрере, а также формировании морального характера [5]. Произвольное поведение, появляющееся в дошкольном возрасте на базе созревания нейроструктур, становится основным механизмом морального развития как осуществления непривлекательного действия ради привлекательной цели или же движение в целом к непривлекательной, но смысловой цели [1]. Ряд экспериментов в классической психологии позволил выделить в качестве принципиального механизма регуляторный компонент морального развития. В частности, этот компонент выделялся в исследованиях склонности к обману и разным формам лжи Хартшорна, Мэя [4] и экспериментах по исследованию френомена «Горькой конфеты» А.Н. Леонтьева [2].

Цель исследования. Моральное развитие изучалось в следующих аспектах: представления дошкольников о моральных и конвенциональных нормах и их иерархии; принятие ребенком моральной нормы и готовность следовать ей вопреки желанию; волевое усилие ребенка в ситуации выбора альтернатив. Таким образом, цель исследования составило изучение взаимосвязи нейропсихологический структур и когнитивных, регуляторных компонентов морального развития. Гипотезами исследования выступили предположения о том, что существует взаимосвязь между 
становлением моральной сфреры ребенка и нейропсихологическим уровнем, обусловленным созреванием и дебютом мозговых структур; а также идея, что существуют различия в способности к соблюдению внешних правил и самоконтролю, отсрочке удовольствия между мальчиками и девочками, связанные с нейропсихологическими особенностями их развития.

Материалы и методы исследования. Исследовательские методики, направленные на оценку нейропсихологического статуса детей: 1) анкета-опросник стандартного протокола нейропсихологического обследования (в сокращенном варианте) для выявления уровня ориентировки и возрастной адекватности поведения детей дошкольного возраста; 2) оценка динамического праксиса (двигательная проба «Кулак-ребро-ладонь» (А.Р.Лурия); графическая проба на динамический праксис (рисунок «Заборчик» (в адаптации Ж.М. Глозман)); 3) изучение межполушарного взаимодействия (проба Н.И. Озерецкого на реципрокную координацию); 4)диагностика произвольной регуляции деятельности (проба на условную реакцию выбора «Кулак-палец» (в адаптации Ж.М. Глозман)); 5) оценка пространственного праксиса (зеркальная проба Хеда); 6) оценка акустического гнозиса (проба ритмических структур (в адаптации Ж.М. Глозман)).

Исследовательские методики, направленные на оценку морального развития старших дошкольников: 1) исследование принятия ребенком моральных норм и ценностей (экспериментальная проба «Горькая конфета» (по А.Н. Леонтьеву); экспериментальная проба по исследованию соблюдения внешних правил «Веревочка» (адаптация Авдуловой Т.П.)); 2) исследование отсроченного удовольствия (адаптация стенфордского эксперимента с маршмеллоу W. Mischel и E.B. Ebbesen); 3) диффреренциация конвенциональных и моральных норм (анкета «Оцени поступок» по Э. Туриэлю).

В исследовании приняли участие 82 ребенка в возрасте от 5 лет и 1 месяца до 6 лет и 4 месяцев. Все дети являются воспитанниками старших групп детских дошкольных образовательных организаций г. Москвы. Среди респондентов 44 мальчика и 38 девочек. Средний возраст обследуемых - 5 лет и 3 месяца. Исследование проводилось совместно с магистрантом О.А.Беловой в рамках работы над магистерской диссертацией.

Результаты исследования. Основная гипотеза исследования полностью подтвердилась: обнаружена взаимосвязь между нейропсихологическим уровнем, обусловленным созреванием и дебютом мозговых структур, и становлением моральной сферы ребенка. Дети с недостаточной сформированностью нейроструктур демонстрируют низкий уровень морального развития. Уровень уверенности в недопустимости нарушения моральных норм статистически значимо положительно связан с уровнем зрелости следующих нейроструктур:

- способностью удерживать и воспроизводить программу (динамический праксис) (Rs = 0,234 (правая рука), $p=0,034 ; R s=0,232$ (левая рука), $p=0,036$ ); 
- способностью оценивать и воспроизводить ритмические структуры (акустический гнозис) (Rs = 0,257, $\mathrm{p}=0,020)$;

- способностью к перешифровке воспринимаемого образа (зрительнопространственный праксис) (Rs = 0,323, $p=0,03)$;

- с уровнем ориентировки (Rs =0,218, $p=0,049$ );

- с уровнем адекватности (Rs $=0,265, p=0,016)$;

- с уровнем критичности (Rs = 0,333, p=0,002);

- латерализацией функций (ведущей рукой) $(\mathrm{Rs}=-0,260, \mathrm{p}=0,018)$.

Большая доля респондентов (40\%) при исследовании способности к принятию моральных норм и ценностей (экспериментальная проба «Горькая конфета») следовала в реальном поведении нормам честности и послушания. Тогда как близкая по численности вторая группа респондентов (35\%), наоборот, нарушила инструкцию, не выказав при этом смущения или стыда, т.е. сложных моральных эмоций, появляющихся в этом возрастном периоде. Существенно меньшая группа (16\%) предпочла соблюсти инструкцию, но при этом попыталась сначала ее нарушить. А 9\% дошкольников, пройдя через сомнения и переживания выбора между реальным лакомством и абстрактным правилом, выбрала нарушение правила, продемонстрировав тем самым низкий уровень принятия моральных норм при формирующихся регуляторных компонентах. Были обнаружены двухсторонние значимые корреляционные связи между нейропсихологическим уровнем и уровнем принятия моральных норм и готовностью следовать им в реальном поведении (экспериментальная проба «Горькая конфрета»): с уровнем критичности (Rs $=-0,247, p=0,025)$.

Уровень регуляции поведения и соблюдения внешних правил дошкольниками (экспериментальная проба «Веревочка») показал двухсторонние значимые корреляционные связи прежде всего с показателями осознания недопустимости нарушения конвенциональных норм и степенью дифференциации конвенциональных и моральных норм (Rs $=0,266, p=0,016$ и Rs $=-0,306, p=0,005$ соответственно). Внешняя регуляция социального поведения связана с преимущественной ориентацией дошкольников на конвенциональные нормы (социальные, в противовес моральным регуляторы) и отрицательно связана со способностью к дифференциации конвенциональных и моральных норм.

С другой стороны, нейропсихологическими предикторами высокого уровня диффреренциации моральных и конвенционалных норм стали зрелая для возраста латерализация (латеральные предпочтения (ведущий глаз): $\mathrm{Rs}=0,298, \mathrm{p}=0,007$ ).

Вторая гипотеза исследования частично подтвердилась. Гипотеза подтвердилась в части различий по нейропсихологическим показателям и уровню следования внешним правилам, а также уровню самоконтроля между мальчиками и девочками в дошкольном возрасте. В части различий по уровню морального развития гипотеза не нашла подтверждения. Были выявлены следующие статистически значимые различия: 
- по шкале «Соблюдение внешних правил»: $U=554,0 ; p<0,05$. Подгруппа мальчиков гораздо больше склонна к явному нарушению внешних правил, тогда как девочки данной подгруппы тяготеют к соблюдению правил;

- по шкале «Динамический праксис»: U = 534,5; p<0,05. В подгруппе девочек способность к воспроизведению программы статистически значимо выше, чем у мальчиков, что может объясняться как большей склонностью следовать предлагаемым условиям, внимательностью, прилежанием и усидчивостью, так и общими более высокими темпами созревания девочек в сравнении с мальчиками;

- по шкале «Самоконтроль и отсрочка удовольствия» (эксперимент с маршмеллоу): $U=554,5 ; p<0,05$. У девочек данный показатель статистически значимо ниже, чем у мальчиков. Девочки более склонны к искушению и немедленному получению удовольствия, чем мальчики.

Согласно полученным в ходе эксперимента с маршмеллоу данным практически половина обследуемой выборки (44\%) продемонстрировала неспособность удержаться от искушения и отложить удовольствие, а смогли удержаться от искушения, используя при этом вспомогательные ресурсы разного рода 28\% старших дошкольников нашей выборки. Часть детей (21\%) пробовали лакомство, не съев его при этом. И лишь 7\% респондентов удержались от искушения, фрактически не использовав вспомогательных ресурсов и продемонстрировали тем самым высокий уровень самоконтроля. При распределении выборки по гендерному признаку было выявлено, что доля девочек, поддавшихся искушению (56\%), существенно превышает долю мальчиков, не удержавшихся и съевших лакомство (34\%). А доля мальчиков, устоявших против искушения и проявивших тем самым высокий уровень самоконтроля (11\%), в пять раз превышает тот же показатель у девочек (2\%).

Обсуждение результатов. Статистический и качественный анализ результатов показал, что на моральное развитие дошкольника оказывают влияние такие нейроструктуры, как формирующиеся зоны префронтального участка коры больших полушарий головного мозга (будущий центр контроля, регуляции и планирования), развитие слухового анализатора и зрелость височной доли головного мозга, а также разветвленного нейрокомплекса (от префронтальной зоны до гиппокампа и базальных ганглиев), связанного с перешифровкой воспринимаемого образа. Так, если ребенок правильно перешифровывает воспринимаемые образы, демонстрируя тем самым склонность к рефлексивному типу мышления, то его степень моральной ответственности и осознания недопустимости нарушения моральных норм находятся на высоком уровне. С другой стороны, чем меньше развито межполушарное взаимодействие, чем менее тренировано мозолистое тело, комиссура, соединяющая оба больших полушария головного мозга, тем более ребенок склонен к нарушению конвенциональных норм (этикета, организационных норм и т.д.). Ребенок с развитым слуховым гнозисом, т.е. сфрормированными по 
возрасту слуховым анализатором и левой височной долей, а также префронтальной зоной коры головного мозга, гораздо меньше склонен к нарушению моральных норм. Сознательная ориентация на моральные нормы, по всей видимости, требует определенной зрелости мозговых структур, в частности, зрительной зоны коры головного мозга, префронтальной зоны, транскортикальных комиссуральных взаимодействий, связанных с работой мозолистого тела, и субкортикальных образований, таких как гиппокамп.

Отдельного внимания заслуживают данные о корреляциях с показателями латерализации функций. Дошкольники с доминированием левополушарных предпочтений более склонны к нарушению моральных норм, нежели дети с правополушарными предпочтениями. Это можно объяснить традиционно более глубокой дифференциацией функций полушарий при левополушарных предпочтениях и более высоким уровнем контроля психических процессов у «правшей» в дошкольном возрасте, а, следовательно, большей склонностью к экспериментированию с нарушением моральных норм (выход на новый уровень осознания моральных норм). Как раз дошкольники с левополушарной латерализацией склонны в большей степени дифференцировать моральные и конвенциональные нормы, т.е. различать морально-этические аспекты и этикетно-организационные правила. Вместе с тем, так как латеральность является не столько количественным показателем, сколько качественным (доминантность правого или левого полушария), статистический анализ закономерностей, связанных с латеральностью, должен строиться с осторожностью.

Важным результатом оказались различия в регуляции поведения между девочками и мальчиками. С одной стороны, уровень зрелости коры головного мозга у девочек выше и показатели регуляции поведения в ряде проб значимо опережают показатели мальчиков. Однако взаимосвязи не линейны. Для девочек принципиально важным оказалась регуляция поведения и следование правилу в социальных (публичных) ситуациях, тогда как в одиночестве девочки чаще следовали «искушению». В отношении мальчиков обнаружена противоположная закономерность. В социальных ситуациях они статистически чаще демонстративно нарушали правило или подвергали его сомнению, тогда как в «Зефирном эксперименте» не только чаще регулировали себя, но и реже прибегали к вспомогательным способам отвлечения от ситуативного желания.

Третьим содержательным результатом исследования стал фракт, что на выборке в 82 ребенка старшего дошкольного возраста ни один ребенок не продемонстрировал классический феномен «Горькой конфеты", то есть не отказался от поощрения в случае нарушения правила. В нашем исследовании процесс «работы совести» проявлялся у детей в момент принятия решения. В процессе выбора, многие дети колебались, пробовали разные стратегии, возвращали игрушку. И в этот момент эмоциональные состояния детей были действительно очень разные: от 
безмятежного нарушения нормы до мучительных сомнений и отказа от действия. На этапе выбора моральные регуляторы проявились достаточно отчетливо.

\section{Литература}

1. Авдулова Т.П., Мотылева Л.А. Динамика морального развития от дошкольного к младшему школьному возрасту. // Психология обучения, 2017, № 10 , с. $42-54$.

2. Леонтьев А.Н. Лекции по общей психологии. - М., 2001.- 511 с.

3. Семенович А.Я. Нейропсихологическая коррекция в детском возрасте. Метод замещающего онтогенеза: Учебное пособие. - 8-е изд. - М., 2015. - 474с.

4. Hartshorne, H. \& May, M. A. (1928). Studies in deceit. New York: Macmillan Co., 1928.

5. Seider S., Novick S., Gomez J. The Effects of Privileging Moral or Performance Character Development in Urban Adolescents. // The Journal of Early Adolescence, Vol. 33, No 6, P. 786-820, 2013. Published by: Sage.

6. Stueber K.R. Varieties of Empathy, Neuroscience and the Narrativist Challenge to the Contemporary Theory of Mind Debate. // Emotion Review, Vol. 4, No 1, P. 55-63, 2012. Published by: Sage.

7. Turiel E. Development of Social Knowledge. Morality \& Convention. Cambridge University Press. 2003.

\section{NEUROPSYCHOLOGICAL BASES OF MORALITY}

Avdulova T. P. (Moscow Pedagogical State University, Moscow, Russia)

The empirical research of the neuropsychological bases of moral development was conducted on sample of 82 children at preschool age. The interrelations between the moral sphere of the children and neuropsychological level were studied. Children with insufficient formation of neurostructures show the weak level of moral development. The following factors of a brain maturity were revealed: ability to hold and reproduce the program (dynamic actions); ability to estimate and reproduce rhythmic structures (acoustic gnosis); ability to a reencryption of the perceived image (visual and spatial actions). Besides, significant differences between boys and girls on neuropsychological indicators and level of following to external rules and also self-control level are found. In moral development the significant differences between boys and girls was not revealed. The low level of the neuropsychological organization was shown by the low level of selfcontrol in real situations at $44 \%$ of children.

Key words: moral development, preschool age, neuropsychology, self-control, knowledge, actions. 